\title{
A portable methane sampling system for radiocarbon-based bioportion measurements and environmental $\mathrm{CH} 4$ sourcing studies
}

\section{Palonen, V.}

2017-07

Palonen , V , Uusitalo , J , Seppälä , E \& Oinonen , M 2017 , ' A portable methane sampling system for radiocarbon-based bioportion measurements and environmental $\mathrm{CH} 4$ sourcing studies ', Review of Scientific Instruments, vol. 88 , no. 7 , 075102 . https://doi.org/10.1063/1.4993920

http://hdl.handle.net/10138/308142

https://doi.org/10.1063/1.4993920

cc_by_nc_sa

publishedVersion

Downloaded from Helda, University of Helsinki institutional repository.

This is an electronic reprint of the original article.

This reprint may differ from the original in pagination and typographic detail.

Please cite the original version. 


\section{A portable methane sampling system for radiocarbon-based bioportion measurements and environmental $\mathrm{CH}_{4}$ sourcing studies}

Cite as: Rev. Sci. Instrum. 88, 075102 (2017); https://doi.org/10.1063/1.4993920

Submitted: 11 December 2016 . Accepted: 02 July 2017 . Published Online: 24 July 2017

V. Palonen (D), J. Uusitalo, E. Seppälä, and M. Oinonen

\section{ARTICLES YOU MAY BE INTERESTED IN}

A portable molecular-sieve-based $\mathrm{CO}_{2}$ sampling system for radiocarbon measurements Review of Scientific Instruments 86, 125101 (2015); https://doi.org/10.1063/1.4936291

A small spacecraft for multipoint measurement of ionospheric plasma

Review of Scientific Instruments 88, 073507 (2017); https://doi.org/10.1063/1.4992022

Integral force feedback control with input shaping: Application to piezo-based scanning systems in ECDLs

Review of Scientific Instruments 88, 075006 (2017); https://doi.org/10.1063/1.4993926

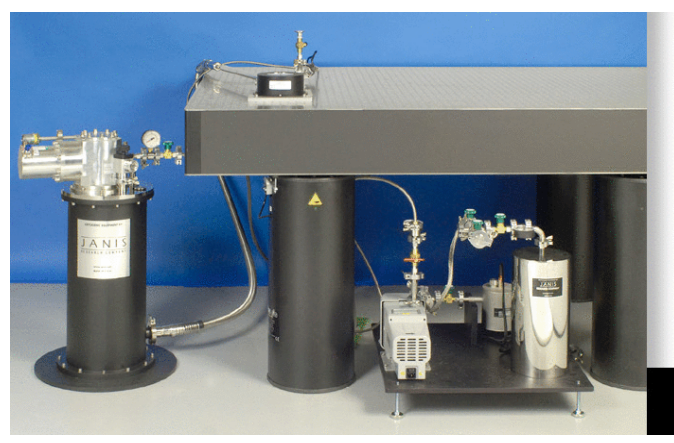

sales@janis.com

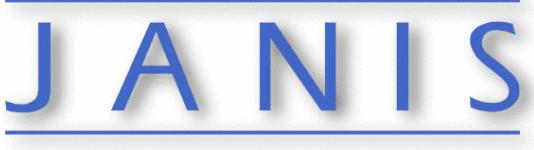

Rising LHe costs? Janis has a solution. Janis' Recirculating Cryocooler eliminates the use of Liquid Helium for "wet" cryogenic systems. 


\title{
A portable methane sampling system for radiocarbon-based bioportion measurements and environmental $\mathrm{CH}_{4}$ sourcing studies
}

\author{
V. Palonen, ${ }^{1,2,3, a)}$ J. Uusitalo,,$^{2,3}$ E. Seppälä, ${ }^{1,3}$ and M. Oinonen ${ }^{2,3}$ \\ ${ }^{1}$ Department of Physics, University of Helsinki, Helsinki, Finland \\ ${ }^{2}$ Finnish Museum of Natural History, University of Helsinki, Helsinki, Finland \\ ${ }^{3}$ Radiocarbon Analytics Finland - RACAF, Helsinki, Finland
}

(Received 11 December 2016; accepted 2 July 2017; published online 24 July 2017)

\begin{abstract}
Radiocarbon measurements can be used to deduce the proportion of renewable to fossil carbon in materials. While these biofraction measurements are performed routinely on solid and liquid substances, measurements of gaseous samples, such as methane, are still scarce. As a pioneering effort, we have developed a field-capable sampling system for the selective capture of $\mathrm{CH}_{4}$ for radiocarbonconcentration measurements. The system allows for biofraction measurements of methane by accelerator mass spectrometry. In environmental research, radiocarbon measurements of methane can be used for fingerprinting different sources of methane emissions. In metrology and industry, biofraction measurements can be utilized to characterize biogas/natural gas mixtures within gas-line networks. In this work, the portable sampling system is described in detail and reference measurements of biofractions of gaseous fuel samples are presented. Low-concentration (1-ppm- $\mathrm{CH}_{4}$ ) sampling for environmental applications appears feasible but has not been fully tested at present. This development allows for multitude of future applications ranging from Arctic methane emissions to biogas insertion to gas networks. Published by AIP Publishing. [http://dx.doi.org/10.1063/1.4993920]
\end{abstract}

\section{INTRODUCTION}

Methane $\left(\mathrm{CH}_{4}\right)$ is relevant for the future of human kind for two reasons. On the one hand, it has a twenty-fold stronger global warming potential as a greenhouse gas compared to carbon dioxide. Understanding its role within the climate change is intertwined with knowledge of sources of emissions-recorded inherently in the eventual fingerprint of atmospheric $\mathrm{CH}_{4}$. On the other hand, $\mathrm{CH}_{4}$ emissions from biogenic waste are more and more converted to biogas, thus contributing to reduction of the fossil carbon emissions. Biogas needs to be transported and distributed within the existing natural gas networks. Mixing of biogas to natural gas networks creates a gas mixture which requires characterization, including its biogenic fraction. Radiocarbon $\left({ }^{14} \mathrm{C}\right)$ concentration measurements provide a quantitative method for ascertaining the proportion of fossil to renewable $\mathrm{CH}_{4}$ to support these sourcing studies and characterizations. ${ }^{1,2}$ Systems for the separation and combustion of $\mathrm{CH}_{4}$ for ${ }^{14} \mathrm{C}$ measurements with Accelerator Mass Spectrometry (AMS) have been developed by several research groups. ${ }^{3-5}$ The methods require high $\mathrm{CH}_{4}$ levels and the systems are operated in a laboratory. In this work, we introduce and commission a portable sampling system for methane for biofraction studies and environmental research. Furthermore, we confirm the capability of our process for biofraction measurements of $\mathrm{CH}_{4}$ with known mixtures of biogas and natural gas samples.

\footnotetext{
a)Electronic mail: vesa.palonen@ helsinki.fi
}

\section{METHODOLOGY}

\section{A. Design specifications}

In addition to atmospheric $\mathrm{CH}_{4}$ sampling, there is a need to sample gas directly from the sources producing $\mathrm{CH}_{4}$ to the atmosphere. Sampling from natural sources includes soil chambers, plant chambers, and low-volume chambers embedded in soil or peat at different depths. Sampling from anthropogenic sources includes $\mathrm{CH}_{4}$ collection from and near the storage containers and transport lines of energy industry, for instance.

Currently, the highest precision for ${ }^{14} \mathrm{C}$ measurements is achieved with Accelerator Mass Spectrometry (AMS) ${ }^{6,7}$ The attained precision is better than $0.2 \%$. Therefore, the developed system is assuming AMS-based biofraction measurements. The required sample size for AMS measurements is typically $1 \mathrm{mg}$ of carbon, while smaller samples down to $50 \mu \mathrm{g}$ can be measured with lower precision. Thus, typically $1.3 \mathrm{mg}$ of $\mathrm{CH}_{4}$ needs to be sampled for successful high-precision measurements. This is a very small sample size for measurement of fuels, yet a large sample size for measurements of environmental methane.

The $\mathrm{CH}_{4}$ concentration of different sources can vary significantly. The $\mathrm{CH}_{4}$ concentration in the atmosphere is currently $1.84 \mathrm{ppm},{ }^{8}$ while the concentration in a closed chamber used for the study of wetland $\mathrm{CH}_{4}$ emissions can be as high as $10000 \mathrm{ppm}$. In industrial applications, $\mathrm{CH}_{4}$ content can be close to $100 \%$. To obtain $1 \mathrm{mg}$ of carbon from $\mathrm{CH}_{4}$ in the atmosphere, roughly one cubic meter of atmospheric air has to be sampled, whereas for industrial sources, only one $\mathrm{cm}^{3}$ (ATM) is needed. For applications involving closed chambers, 
selective capture of $\mathrm{CH}_{4}$ is important since the removal of large amount of gas will introduce pressure drops to the chambers, which in turn causes leakage flows to the chamber and can disrupt the gas balance of the system.

The large volume of air to be sampled in the lowconcentration cases has up to now limited ${ }^{14} \mathrm{C}$ studies done and hence research has concentrated on the high concentration cases. ${ }^{5,9}$ To enable $\mathrm{CH}_{4}$ collection for ${ }^{14} \mathrm{C}$-AMS measurements from most sources with the same well-tested system, we opted for a selective molecular sieve-based $\mathrm{CH}_{4}$ sampling system. The setup is based on several years of experience with $\mathrm{CO}_{2}$ sampling with molecular sieves. ${ }^{10,11}$ In this system, $\mathrm{CO}_{2}$ is first removed from the target gas, $\mathrm{CH}_{4}$ is then catalytically combusted to $\mathrm{CO}_{2}$, and then a $\mathrm{CO}_{2}$-selective molecular sieve material is used to trap the resulting $\mathrm{CO}_{2}$. Eventually, $\mathrm{CO}_{2}$ is converted to pure carbon and ${ }^{14} \mathrm{C}$ concentration is measured with the AMS method.

\section{B. Overview of the sampling system}

A schematic of the sampling system is shown in Fig. 1, along with a biogas and fossil gas mixer for production of bioportion reference samples. List of the main components of the setup is given in Table I

In summary, the source gas is first taken through a Nafion dryer to remove water. Then, the gas goes through two large $13 \mathrm{X}$ molecular sieve cartridges, which remove the contaminating $\mathrm{CO}_{2}$. This is followed by a miniature oven for combustion, which converts $\mathrm{CH}_{4}$ to $\mathrm{CO}_{2}$. A Li-840A CO $2 / \mathrm{H}_{2} \mathrm{O}$ analyzer measures the amount of resulting $\mathrm{CO}_{2}$ and $\mathrm{H}_{2} \mathrm{O}$, and finally a smaller $13 \mathrm{X}$ sieve cartridge traps $\mathrm{CO}_{2}$ from the combustion of $\mathrm{CH}_{4}$. These stored $\mathrm{CO}_{2}$ samples can then be chemically converted to pure carbon ${ }^{12}$ and measured for radiocarbon in an AMS facility. ${ }^{7}$

Figure 2 presents photos of the system in laboratory use and in use at the Siikaneva bog near the environmental-research SMEAR II station in Finland. The system can be either batteryoperated, one battery lasting roughly $6 \mathrm{~h}$ of operation, or connected to a $230 \mathrm{~V}$ plug.

\section{Details of the sampling setup}

The Nafion dryer drops the $\mathrm{H}_{2} \mathrm{O}$ concentration in the flow to below $1 \mathrm{ppt}$. The dryer is used in the reflux mode. This means that, after the $\mathrm{H}_{2} \mathrm{O}$ removal and $\mathrm{CO}_{2}$ capture, the dry sample gas is returned back to the dryer, flowing outside of the Nafion tubing as the purge gas is in a significantly lower pressure. The pressure is lower in the purge side of the dryer because the purge side of the dryer sits between the diaphragm pump and the flow controller (labeled FC in the figure). The flow controller limits the flow and therefore creates a pressure step. The upstream side (inside of the Nafion tubing) is at roughly the same pressure as the target chamber, while the downstream side (the dryer purge side) is at roughly 300 mbar with a typical flow rate of $1 \mathrm{l} / \mathrm{min}$. Most of $\mathrm{H}_{2} \mathrm{O}$ penetrates the tube wall to the low-pressure-side of the dryer and is not captured in the molecular sieve cartridge. This has also an advantage in field collections since it minimizes the drying of the collection chamber air during operations, as $\mathrm{H}_{2} \mathrm{O}$ is returned back to the chamber volume.

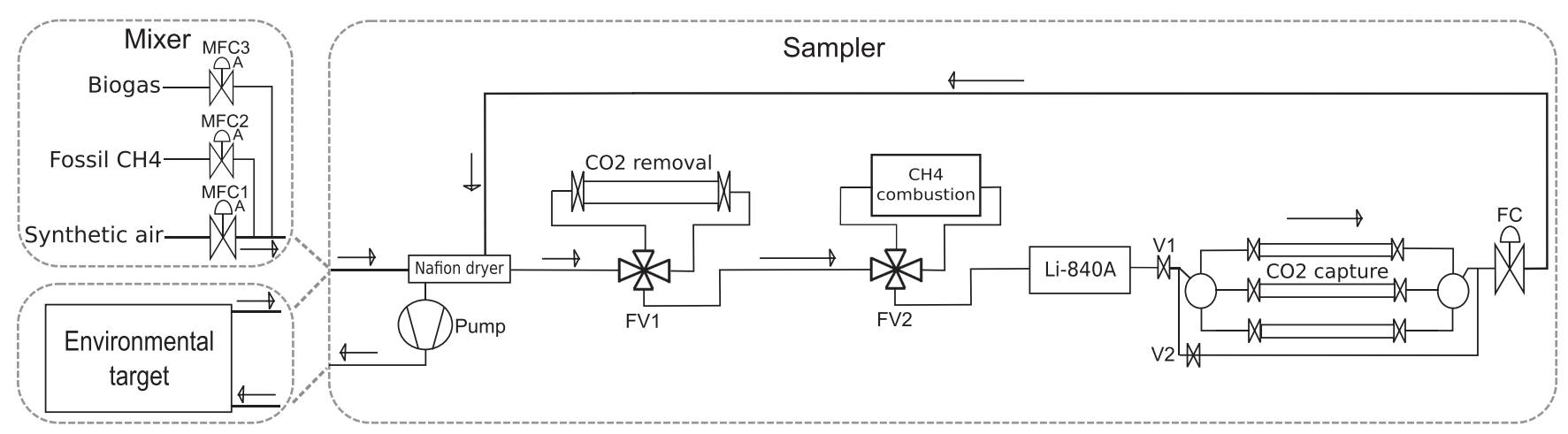

FIG. 1. A schematic diagram of the molecular-sieve based $\mathrm{CH}_{4}$ sampling system. Samples can be taken from most targets. The biogas and fossil gas mixer setup used for making reference samples is shown separately, along with how an environmental research chamber is attached to the setup.

TABLE I. List of the main off-the-shelf components in the setup.

\begin{tabular}{ll}
\hline \hline Label & Description \\
\hline Pump & Diaphragm pump, KNF NMP 850.1.2 KNDC B \\
Nafion dryer & Nafion dryer used in the reflux mode, Perma pure PD-200T-12MSS \\
FV1 & Four-way valve for including/bypassing $\mathrm{CO}_{2}$ removal, Swagelok SS-43YF2 \\
FV2 & Four-way valve for including/bypassing $\mathrm{CH}_{4}$ combustion, Swagelok SS-43YF2 \\
LI-840A & $\mathrm{CO}_{2} / \mathrm{H}_{2} \mathrm{O}$ analyzer, LICOR LI-840A \\
V1, V2 & Ball valve, Swagelok SS-42GS6MM-1466 $_{\text {FC }}$ \\
MFC1 & Sample flow controller, Swagelok VAF-G2-07L \\
MFC2, MFC3 & Mass flow controller for synthetic air, Vögtlin GSC-B9TA-FF21 \\
\hline \hline
\end{tabular}



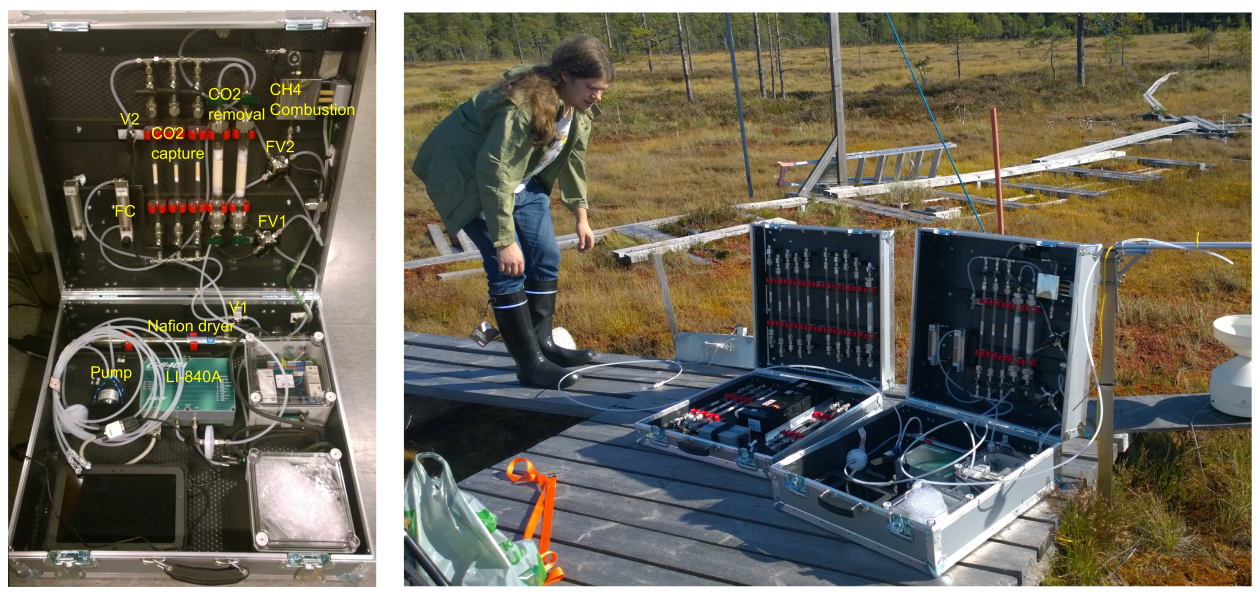

FIG. 2. Pictures of the molecular-sieve based $\mathrm{CH}_{4}$ sampling system at the lab and in the field. Labels according to the schematic (Fig. 1) and part list (Table I) included to the first picture.

There are currently no suitably selective molecular sieves available for $\mathrm{CH}_{4}$. This is due to the relative similarity in size and polarity of the $\mathrm{CH}_{4}$ molecule to much more abundant molecules like $\mathrm{N}_{2}$. This led us to develop the $\mathrm{CH}_{4}$ collection system based on our tested $\mathrm{CO}_{2}$ system, where $\mathrm{CH}_{4}$ is combusted to $\mathrm{CO}_{2}$ and then selectively trapped. The most common sieve material used with $\mathrm{CO}_{2}$ is $13 \mathrm{X}$ zeolite due to its high selectivity for $\mathrm{CO}_{2},{ }^{13,14}$ well studied properties, and commercial availability in various mesh sizes. In addition, based on our previous work ${ }^{15}$ with residual gas analyses, we understand the characteristics of this molecular sieve material extremely well. Therefore, we use a $13 \mathrm{X}$ sieve material for both removal of contaminating $\mathrm{CO}_{2}$ (Merck 13X beads, 1.05703.1000) and for later trapping of combusted $\mathrm{CO}_{2}$ (Supelco Analytical 13X, 45/60 Mesh, 2-0304).

The combustion unit consists of a tubular miniature oven. The oven size is $70 \times 70 \times 70 \mathrm{~mm}$, with a 6-mm-OD (4-mmID) quartz tube running through. Combustion is usually done at $600{ }^{\circ} \mathrm{C}$, with $20 \mathrm{mg}$ of $\mathrm{Pd} / \mathrm{Al}_{2} \mathrm{O}_{3}$ catalyst. The catalyst was fixed via quartz wool with a slight bottleneck in the combustion tube downstream. The efficiency of combustion depends on the flow rate used, measurements of which are shown in a Sec. III A.

After combustion, the $\mathrm{CO}_{2} / \mathrm{H}_{2} \mathrm{O}$ analyzer $(\mathrm{Li}-840 \mathrm{~A}$ ) is used to measure the $\mathrm{CO}_{2}$ and $\mathrm{H}_{2} \mathrm{O}$ concentrations in the flow and hence the amount of $\mathrm{CH}_{4}$ in the original gas flow. In addition, the analyzer is used to check that the $\mathrm{CO}_{2}$ removal prior to combustion is sufficient by bypassing the $\mathrm{CH}_{4}$ combustion module. The analyzer can also be used to measure the $\mathrm{CO}_{2}$ and $\mathrm{H}_{2} \mathrm{O}$ levels in the original gas by bypassing both $\mathrm{CO}_{2}$ removal and $\mathrm{CH}_{4}$ combustion modules. The $\mathrm{CO}_{2}$ concentration measurement also enables one to see that the collected amount of carbon is sufficient for an AMS sample (0.1-1 mg of carbon). Graphical user interface and data logging of the Li-840A are handled with a rugged tablet personal computer (PC) (Xplore Bobcat, IP 65), which is also used for note-taking during sampling.

After the $\mathrm{CO}_{2} / \mathrm{H}_{2} \mathrm{O}$ analyzer, the sample gas is taken through the sieve cartridge (see Fig. 3), which is a vacuumtight quartz tube containing roughly $1 \mathrm{~g}$ of $13 \mathrm{X}$ molecular sieve grains, which traps all of $\mathrm{CO}_{2}$ and $\mathrm{H}_{2} \mathrm{O}$ from $\mathrm{CH}_{4}$ combustion.
A quartz filter has been melted to the quartz tube to hold the sieve material in place. Another quartz filter has been installed to the inlet of the cartridge to make sure no carbonaceous particles enter the cartridge.

Usually, a $\mathrm{CO}_{2}$ sample is collected with a $1 \mathrm{l} / \mathrm{min}$ flow rate, at which flow the Nafion dryer is efficient with 1 ppt $\mathrm{H}_{2} \mathrm{O}$. With these cartridges, complete capture of $\mathrm{CO}_{2}$ occurs up to 101 of 1-bar 1-ppt- $\mathrm{H}_{2} \mathrm{O} 400-\mathrm{ppm}-\mathrm{CO}_{2}$ gas, ${ }_{15}$ defining a maximum of over $2 \mathrm{mg}$ of carbon for one cartridge. This is over twice the amount of carbon necessary for high-precision ${ }^{14} \mathrm{C}$-AMS measurements. With the optimized sieve desorption procedure, ${ }^{15}$ based on the amount of $\mathrm{CO}_{2}$ retrieved from blank sieve cartridges, the background from the sieve cartridges is below $2 \mu \mathrm{g} \mathrm{C}$. The low background contribution is also seen in the routinely measured 0.15-0.20 pMC (without background correction) ${ }^{14} \mathrm{C}$ concentrations from combustion and sieve collection from natural gas samples.

To be easily reproducible, the setup uses mainly commercial components. The flexible parts of the tubing are 6-mm-OD polyethylene tubes and the fixed parts are made from Synflex tubing. Most fittings are standard Swagelok fittings with reusable PTFE (Teflon) ferrules, enabling easy re-configurations of the system in the field if necessary.

Three $\mathrm{CH}_{4}$ samples can be collected in one go. After three samples, the three sieve containers are removed and new containers are put in. After the $\mathrm{CO}_{2}$ collection, the source gas is circulated back to the chamber or to the atmosphere. Because the gas in the system can easily be flushed to remove $\mathrm{CH}_{4}$ and $\mathrm{CO}_{2}$ remaining in the tubing from a previous sampling, the system is zero dead-volume with respect to $\mathrm{CH}_{4}$ sampling.

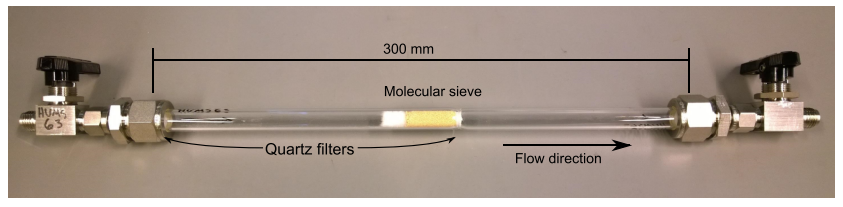

FIG. 3. A molecular sieve cartridge used to selectively trap $\mathrm{CO}_{2}$ from the gas flow. Reproduced with permission from Rev. Sci. Instrum. 86, 125101 (2015). Copyright 2015 AIP Publishing LLC. 


\section{D. $\mathrm{CO}_{2}$ removal}

As discussed, for ease of operation, we use larger molecular sieve containers to remove $\mathrm{CO}_{2}$ from the sample gas prior to combustion. We use two $300 \mathrm{~mm}$ long and 25-mm-OD cartridges, similar to those used for sampling (Fig. 3), but with $20 \mathrm{~g}$ of sieve material instead of $1 \mathrm{~g}$. The removal capacity is enough for $12 \mathrm{~h}$ of sampling with $400-\mathrm{ppm}-\mathrm{CO}_{2}$ air. The removal is almost complete, with $1 \mathrm{~h}$ of sampling contributing less than $1 \mu \mathrm{g}$ of $\mathrm{C}$ from $\mathrm{CO}_{2}$. Removal capacity is hence $530 \mathrm{mg}$ of $\mathrm{CO}_{2}$ (13 mg per $1 \mathrm{~g}$ of sieve material), after which the $\mathrm{CO}_{2}$ capture is not sufficient and the cartridges have to be changed. The solution is practical because no caustic materials are used and the cartridges can be renewed simply by attaching them to a vacuum line and heating.

\section{E. CO interference}

While $\mathrm{CO}_{2}$ is removed adequately by the larger molecular sieve containers prior to the $\mathrm{CH}_{4}$ combustion, other hydrocarbons and notably carbon monoxide are not removed from the flow. We were not able to find relevant data on $\mathrm{CO}$ adsorption to molecular sieves, so we measured the adsorption using synthetic air with 20-ppm CO and a $\mathrm{CO}$ detector. The adsorption negligible, i.e., less than $5 \%$ of $\mathrm{CO}$, is removed from $0.5 \mathrm{l} / \mathrm{min}$ flow with $10 \mathrm{~g}$ of $13 \mathrm{X}$ or $5 \mathrm{~A}$ molecular sieve material. As $\mathrm{CO}$ is easily combusted to $\mathrm{CO}_{2}$, carbon from $\mathrm{CO}$ will be included in the final sample in addition to carbon from $\mathrm{CH}_{4}$. For the atmosphere, the concentration of $\mathrm{CO}$ is roughly twenty times lower than that of $\mathrm{CH}_{4}$, and for several environmental targets (i.e., wetland gas collection), $\mathrm{CO}$ levels are negligible to $\mathrm{CH}_{4}$ levels. In addition, the two gases are not expected to have very different ${ }^{14} \mathrm{C}$ concentrations. However, for many applications, this will be an issue, ${ }^{4}$ and in the future, CO removal will be added with, e.g., a Sofnocat 423 (Molecular Products Group LTD, Essex, United Kingdom) oxidizer installed to the $\mathrm{CO}_{2}$ removal-block prior to the $\mathrm{CO}_{2}$ scrubs.

\section{F. Reference samples}

Samples of natural gas and biogas were collected in collaboration with Gasum Oy as follows. Gas samples were collected in the natural gas and biogas facilities of Gasum Oy into 3.785 1 Swagelok 304L-HDF4-1GAL-PD double-ended cylinders equipped with Swagelok SS-16DPM4-F4-BC-PD valves in both ends and with $6 \mathrm{~mm}$ Swagelok SS-6M0-1-4 connector. The cylinders were connected into the $6 \mathrm{~mm}$ sampling tube at the gas facility and the cylinder was flushed through first with 40 bars line pressure for $1 \mathrm{~min}$. The outlet valve was then closed and gas with the pressure of 40 bars was collected into the cylinder for $5 \mathrm{~min}$. The inlet valve was closed to store the sample in the cylinder. Based on our experience in sampling the gas, we consider such double-ended cylinders of various sizes to be very convenient in taking samples from natural gas or biogas facilities and delivery points (see also below).

The natural gas (assumed to be $100 \%$ fossil) was collected at Gasum natural gas facility at Imatra close to the Russian border. The natural gas consumed in Finland is imported along a pipeline from the Western-Siberian gas fields of Yamburg
TABLE II. Contents of the gas samples (in mol. \%).

\begin{tabular}{lcc}
\hline \hline Gas & $\begin{array}{c}\text { Natural gas } \\
\text { Concentration (mol. \%) }\end{array}$ & $\begin{array}{c}\text { Biogas } \\
\text { Concentration (mol. \%) }\end{array}$ \\
\hline Methane & 96.19 & 97.75 \\
Ethane & 2.32 & 0.00 \\
Propane & 0.50 & 0.00 \\
i-butane & 0.09 & 0.00 \\
n-butane & 0.07 & 0.00 \\
i-pentane & 0.01 & 0.00 \\
n-pentane & 0.01 & 0.00 \\
Hexane & 0.01 & 0.00 \\
Nitrogen & 0.66 & 0.49 \\
Carbon dioxide & 0.14 & 1.51 \\
Oxygen & 0.00 & 0.25 \\
\hline \hline
\end{tabular}

and Urengoy to the Imatra reception station. ${ }^{16}$ The location was selected to maximize the distance from the sampling site to the Finnish biogas facilities and thus to avoid any biogas backflow into the gas pipeline. This would have affected the biofraction measurements. The biogas sample was collected at Gasum biogas facility at Kujala, Lahti, Finland. The facility produces biogas from biowaste collected from homes, retailers, and industry as well as sludge from purification plants in the Lahti region and elsewhere in Southern Finland. ${ }^{17}$ The contents of the gases are given in Table II.

\section{G. Reference biofraction samples and measurements}

Our setup allows us to mix the above reference gases to provide any biogas/natural gas mixtures. To demonstrate the success of our process to perform ${ }^{14} \mathrm{C}$-AMS-based biofraction analyses, we mixed reference gases with $100 \%$ (pure biogas), $50 \%, 30 \%, 10 \%$, and $0 \%$ (pure natural gas) biofractions. Biogenic content of the mixtures was calculated based on the flow rates of the automatic mass flow controllers (Vögtlin GSCA9TA-FF21). The uncertainties for the mixing ratios were calculated by propagating the repeatability estimates given by the manufacturer (accuracy $0.2 \%$ of full scale). Calculated biogenic contents were corrected for the real carbon content of the gases (Table II). This is essential since the radiocarbon method determines the biocarbon fraction.

After combustion and sampling, the $\mathrm{CO}_{2}$ samples were converted to graphite ${ }^{12}$ and measured for their ${ }^{14} \mathrm{C}$ concentration at the Helsinki accelerator mass spectrometry (HAMS) facility. ${ }^{7}$

Biofraction analyses were performed according to ASTM D6866-16 standard by dividing the measured radiocarbon concentration by a reference value for the year 2015 $(\mathrm{REF}=102.0)$. In addition, true biofractions have been given assuming the measured ${ }^{14} \mathrm{C}$ concentration for the $100 \%$ biogas sample to correspond to the true biogenic content of the biogas.

\section{RESULTS}

\section{A. Combustion efficiency}

Palladium- and platinum-based catalysts are considered to be excellent for low-temperature combustion of methane. ${ }^{18}$ 
However, the catalyst performance is influenced by various conditions, such as the gas mixture composition. Hence, for example, Pd-based catalysts are more suitable for oxygen-rich conditions, whereas Pt-based catalysts perform better in fuelrich conditions. ${ }^{19}$ Therefore, to find the most efficient catalyst for our purpose, we performed preliminary combustion tests using commercial $\mathrm{Pd} / \mathrm{Al}_{2} \mathrm{O}_{3}$ (Alfa Aesar, Product No. 11711 and 89 114) and $\mathrm{Pt} / \mathrm{Al}_{2} \mathrm{O}_{3}$ (Alfa Aesar, Product No. 11797 and 89 106) catalysts both in powder- and pellet-forms. Based on these initial tests, $\mathrm{Pd} / \mathrm{Al}_{2} \mathrm{O}_{3}$ in powder-form proved to be the most suitable.

Figure 4 shows the measured combustion efficiencies as a function of oven temperature and flow rate for $20 \mathrm{mg}$ of $\mathrm{Pd} / \mathrm{Al}_{2} \mathrm{O}_{3}$ powder at the center of the combustion tube. The efficiency was determined from the known concentration of incoming $\mathrm{CH}_{4}$ (controlled by the mass flow meters and seen from the attained plateau for higher oven temperatures) and from the concentration of outgoing $\mathrm{CO}_{2}$ (measured by the LI-840A in the sampling system). The tests were done with $0.5 \%-\mathrm{CH}_{4} 20 \%-\mathrm{O}_{2}$ synthetic air. (Synthetic air is used here to provide oxygen for combustion because the samples are almost pure $\mathrm{CH}_{4}$, cf. the mixer in Fig. 1.) No notable differences were observed in the combustion efficiency in tests with lower 500-ppm- $\mathrm{CH}_{4}$ concentrations.

\section{B. Results from biofraction measurements}

The results of the biofraction measurements are given in Table III and Fig. 5. Overall, the biofractions determined according to ASTM D6866-16 standard are equal compared to the mixed biofractions. Particularly, the average difference between measured and mixed biofractions is $0.1 \%$-units, the maximum difference being $0.6 \%$-units. Thus the average difference is smaller than the typical statistical uncertainty of an individual measurement $(0.1 \%-$ $0.6 \%$ in our set). Furthermore, both the individual statistical

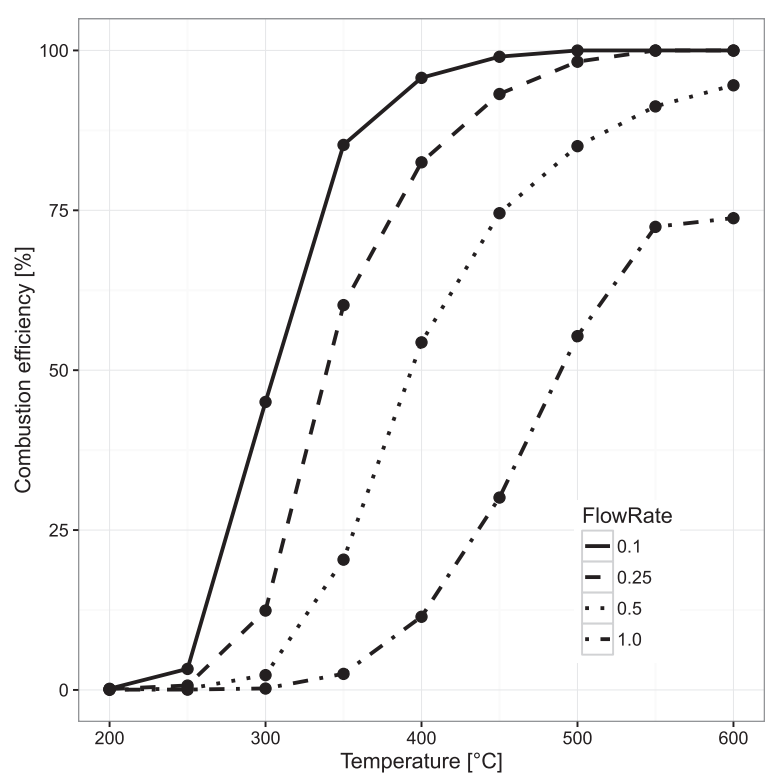

FIG. 4. Combustion efficiency for the currently used catalyst $(20 \mathrm{mg}$ of $\mathrm{Pd} / \mathrm{Al}_{2} \mathrm{O}_{3}$ powder) as a function of oven temperature and flow rate. Flow rates given in $1 / \mathrm{min}$.
TABLE III. ${ }^{14} \mathrm{C}$-measured biofractions for different mixtures of biogas and natural gas. The ${ }^{14} \mathrm{C}$ concentrations have been corrected with the sample preparation background value of $0.4 \pm 0.1 \mathrm{pMC}$, measured routinely in the laboratory.

\begin{tabular}{lccc}
\hline \hline $\begin{array}{l}\text { Mixed } \\
\text { biogas/natural } \\
\text { gas ratio (\%) }\end{array}$ & $\begin{array}{c}{ }^{14} \text { C concentration, } \\
\text { percent modern } \\
\text { carbon (\%) }\end{array}$ & $\begin{array}{c}\text { Biofraction (\%), } \\
\text { ASTM D6866-16 }\end{array}$ & $\begin{array}{c}\text { Biofraction (\%), } \\
\text { true }\end{array}$ \\
\hline $100.0 \pm 0.0$ & $104.47 \pm 0.55$ & $100.0 \pm 0.6$ & $100.0 \pm 0.6$ \\
$49.7 \pm 1.4$ & $51.36 \pm 0.30$ & $50.4 \pm 0.3$ & $49.2 \pm 0.4$ \\
$29.8 \pm 1.1$ & $29.86 \pm 0.29$ & $29.3 \pm 0.3$ & $28.6 \pm 0.4$ \\
$9.9 \pm 1.0$ & $10.28 \pm 0.14$ & $10.1 \pm 0.2$ & $9.8 \pm 0.2$ \\
$0.0 \pm 0.0$ & $0.06 \pm 0.07$ & $0.1 \pm 0.1$ & $0.1 \pm 0.1$ \\
\hline \hline
\end{tabular}
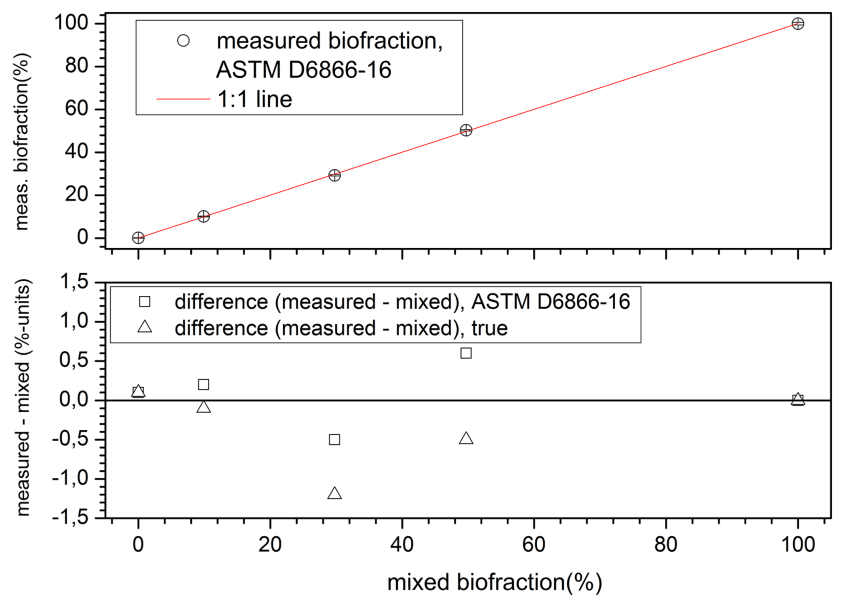

FIG. 5. Correlation of the measured biofraction and the mixed biofraction.

uncertainty and the systematic difference are clearly less than the inter-laboratory total uncertainty of $3 \%$ (abs) discussed within the recent ASTM D6866-16 standard. ${ }^{20}$ It seems that the measurement process is thus well within the existing standardization.

\section{DISCUSSION}

With the currently used catalyst, combustion was seen to be complete for flow rates less than $0.3 \mathrm{l} / \mathrm{min}$ in the usual operating temperature of $600^{\circ} \mathrm{C}$. For higher flow rates, the incomplete combustion may cause isotopic fractionation. Usually this will not be a problem, as radiocarbon results are always corrected for fractionation based on the measured ${ }^{13} \mathrm{C} /{ }^{12} \mathrm{C}$ ratios for each sample. The attained combustion efficiency is hence sufficient for most applications. However, to reduce the sampling time for low-concentration samples, the possibilities for improved catalysis will be studied in a future paper.

$100 \%$ biogas sample provided radiocarbon concentration (pMC value) of $104.47(55) \%$ which means about 5\% above the reference level of the year 1950 and 2.5\%-units higher concentration compared to the present atmospheric level assumed as $102 \%$. This corresponds (in average) to few years old material from which the biogas was produced. The value seems to be very realistic since part of the biogenic waste contains woodbased products that have variable age-distributions bringing in 
older carbon than contained in the 1-2 yr old biogenic waste. $100 \%$ natural gas $(0 \%$ biogas) sample resulted in radiocarbon concentration (pMC value) of $0.06 \pm 0.07 \mathrm{pMC}$. This practically equals to 0 that is also expected since the fossil natural gas is millions of years old and contains no radiocarbon due to ${ }^{14} \mathrm{C}$ half-life of only $5730 \mathrm{yr}$.

The test between the ASTM-based and true results (Table III) illustrates that for the true values, one obtains a similar overall agreement with the known mixing ratio compared to ASTM-based values. Only exception is $30 \%$ mixture for which the true measured biofraction is too small by $1.2 \%$-units (Fig. 5), while still being within the estimated interlaboratory uncertainty (see above). The slight differences obtained illustrate the importance of knowing the intrinsic age of the biogenic material since the atmospheric ${ }^{14} \mathrm{C}$ concentration still gradually decreases after the 1960s bomb pulse. Therefore, we appreciate the changes made to the recent version (ASTM D6866- $16^{20}$ ) of the biofraction standardization to take these changes into account.

\section{CONCLUSIONS}

The molecular-sieve-based system for collecting $\mathrm{CH}_{4}$ samples for radiocarbon-based biofraction analyses has been successfully developed and commissioned at the University of Helsinki, Finland, under the Radiocarbon Analytics Finland (RACAF) process organization.

Compared to the commonly used flask sampling, the present sampling system utilizing molecular sieve cartridges has several advantages. First, because the setup selectively traps $\mathrm{CH}_{4}$ (and $\mathrm{CO}_{2}, \mathrm{H}_{2} \mathrm{O}$ ) from the target gas, targets with very different $\mathrm{CH}_{4}$ concentrations can be sampled. Importantly, the system seems to enable sampling from low $\mathrm{CH}_{4}$ concentration targets such as the atmosphere. Second, the system does not introduce significant underpressures to target when sampling from closed volumes. Third, the size of the sieve cartridges is small. This enables sampling several targets with one portable system. Fourth, the small volume and vacuum-tightness of the sieve cartridges enable long storage of the samples after collection. An added benefit is that the attached Li-840A analyzer enables the calculation of the $\mathrm{CH}_{4}$ flux to a target chamber when such information is required.

Biofraction measurements of in-house reference samples, i.e., known mixtures or modern biogas and fossil natural gas, demonstrated the capability of the setup. Specifically, measurement errors were within the limits of existing standardization. We conclude that the overall process of sampling, combusting, storing, graphitization, and AMS measurements provides high-quality radiocarbon and biofraction measurements on gaseous samples of biogas, natural gas, or environmental methane. The development allows for multitude of future applications ranging from Arctic methane emissions to measurements of, e.g., biogas insertion and distribution within existing natural gas networks.
In our future work, special emphasis will be given in optimizing the catalyst properties separately for each use case by taking into account the various underlying conditions (e.g., gas mixture composition) and their effects on the combustion. Importantly, for several environmental applications, $\mathrm{CO}$ removal will be added to the $\mathrm{CO}_{2}$ removal block of the system to get rid of $\mathrm{CO}$ contribution when necessary.

\section{ACKNOWLEDGMENTS}

The authors thank the technical personnel the Division of Materials Physics, UoH for their help in design and for the installation of the electrical components of the sampling system. The authors are also grateful to the technical personnel of the Laboratory of Chronology for various samplepreparatory tasks and for the associated $\delta^{13} \mathrm{C}$ measurements. EURAMET is acknowledged for providing part of the funding for the current research as part of the ENG54 Biogas Metrology for biogas-project. The energy company Gasum Oy and especially its service technician Pasi Toivonen are acknowledged for providing the fossil and biogas reference gases.

${ }^{1}$ J. D. Kessler, W. S. Reeburgh, J. Southon, and R. Varela, Geophys. Res. Lett. 32, doi:10.1029/2005GL022984 (2005).

${ }^{2}$ M. H. Garnett, S. M. L. Hardie, C. Murray, and M. F. Billett, Biogeochemistry 114, 213-223 (2013).

${ }^{3}$ M. A. Pack, X. Xu, M. Lupascu, J. D. Kessler, and C. I. Czimczik, Org. Geochem. 78, 89 (2015).

${ }^{4}$ V. Petrenko, A. Smith, G. Brailsford, K. Riedel, Q. Hua, D. Lowe, J. P. Severinghaus, V. Levchenko, T. Bromley, R. Moss, J. Mühle, and E. J. Brook, Radiocarbon 50, 53 (2008).

${ }^{5}$ M. Garnett, S. Hardie, and C. Murray, Soil Biol. Biochem. 50, 158 (2012).

${ }^{6}$ V. Palonen and P. Tikkanen, Nucl. Instrum. Methods Phys. Res., Sect. B 361, 263 (2015).

${ }^{7}$ P. Tikkanen, V. Palonen, H. Jungner, and J. Keinonen, Nucl. Instrum. Methods Phys. Res., Sect. B 223-224, 35 (2004).

${ }^{8}$ Ed. Dlugokencky, NOAA/ESRL Trends in Atmospheric Methane, http:// www.esrl.noaa.gov/gmd/ccgg/trends_ch4/, 2016.

${ }^{9}$ M. H. Garnett, P. Gulliver, and M. F. Billett, Ecohydrology 9, 113 (2015).

${ }^{10}$ K. Hämäläinen, H. Fritze, H. Jungner, K. Karhu, M. Oinonen, E. Sonninen, P. Spetz, M. Tuomi, P. Vanhala, and J. Liski, Nucl. Instrum. Methods Phys. Res., Sect. B 268, 1067 (2010).

${ }^{11}$ V. Palonen, Rev. Sci. Instrum. 86, 125101 (2015).

${ }^{12}$ V. Palonen, A. Pesonen, T. Herranen, P. Tikkanen, and M. Oinonen, Nucl. Instrum. Methods Phys. Res., Sect. B 294, 182 (2013).

${ }^{13}$ J. E. Bayer, P. M. Williams, and E. R. M. Druffel, Anal. Chem. 64, 824 (1992).

${ }^{14}$ S. M. L. Hardie, M. H. Garnett, A. E. Fallick, A. P. Rowland, and N. J. Ostle, Radiocarbon 47, 441 (2005).

${ }^{15}$ V. Palonen, Radiocarbon 55, 416 (2013).

${ }^{16}$ Gasum Oy, Natural energy gas transmission pipelines, http://www.gasum. com/Facts-about-gas-/Natural-gas/Natural-gas-delivery/, 2016.

${ }^{17}$ Gasum Oy, Energy of the future already available today, http://www. gasum.com/Facts-about-gas-/Biogas/, 2016.

${ }^{18}$ J. H. Lee and D. L. Trimm, Fuel Process. Technol. 42, 339 (1995).

${ }^{19}$ R. Burch and P. K. Loader, Appl. Catal., B 5, 149 (1994).

${ }^{20}$ ASTM D6866-16, Standard Test Methods for Determining the Biobased Content of Solid, Liquid, and Gaseous Samples Using Radiocarbon Analysis (ASTM International, West Conshohocken, PA, 2016), www.astm.org. 